\title{
Switching Magnetic Properties by a Mechanical Motion
}

\author{
Benjamin Doistau, Lorien Benda, Bernold Hasenknopf, Valérie Marvaud and \\ Guillaume Vives * \\ Institut Parisien de Chimie Moléculaire, Sorbonne Université, CNRS UMR 8232, 4 Place Jussieu, 75005 Paris, \\ France; benjamin.doistau@unige.ch (B.D.); lorien.benda@upmc.fr (L.B.); bernold.hasenknopf@upmc.fr (B.H.); \\ valerie.marvaud@upmc.fr (V.M.) \\ * Correspondence: guillaume.vives@upmc.fr; Tel.: +33-1-4427-3960
}

Received: 6 December 2017; Accepted: 26 December 2017; Published: 2 January 2018

\begin{abstract}
Switching magnetic properties have attracted a wide interest from inorganic chemist for the objectives of information storage and quantum computing at the molecular level. This review is focused on magnetic switches based on a mechanical motion, which is an innovative approach. Three main strategies to control magnetic properties by a mechanical motion have been developed in the literature and will be described. The first one (ligand-induced spin change) consists in modulating the ligand field strength by a configuration change of the ligand in spin-crossover complexes. The second one (coordination-induced spin-state switching) is based on a change in the coordination number of a metallic center that is triggered by the motion of one ligand. The third one uses the modulation of the exchange interaction between two spin-centers by a mechanical motion.
\end{abstract}

Keywords: molecular switch; magnetism; molecular machine; spin crossover; photoisomerization; LD-LISC; LD-CISSS

\section{Introduction}

A current trend in physical, chemical, and biological sciences is the pursuit of miniaturized machinery and devices. To achieve this goal, two complementary approaches have been developed. The first one, called 'top-down', consists in the miniaturization of existing objects following lithographic technologies, and has been widely used in microelectronics. This approach is currently reaching some physical limits due to the incompatibility of such technologies with the nanometer scale. The second one, known as the 'bottom-up', starts from atoms and molecules and follows a building up strategy, consisting in the association of different modular functional units through the formation of covalent bonds or supramolecular interactions. Nature already uses this strategy to build a large variety of sophisticated machines, such adenosine triphosphate (ATP) synthase, kinesin, myosin, DNA polymerase, or ribosome, which are designed to perform linear or rotary motion [1]. Inspired by nature or their man-made macroscopic analogues a variety of artificial molecular machines have been synthetized [1,2]. By analogy with a macroscopic machine, a molecular machine can be defined as an assembly of molecular components designed to perform a mechanical motion (i.e., a controlled large amplitude or directional movement of one component relative to another) in response to a stimulus. Even if the manipulation of motion at the molecular level has been mastered in such molecular machines, the reversible control of physical or chemical properties at the molecular level remains a challenge in the field. In particular, switching magnetic properties has attracted a wide interest from inorganic chemist for information storage or quantum computing at the molecular level.

Several stimuli have been used to trigger magnetic properties changes [3] in three main areas: (i) changing the spin state of a transition metal in spin crossover (SCO) systems [4-11]; (ii) switching the exchange interaction between different spin carriers [12,13]; and (iii) switching single-molecule 
magnet (SMM) properties [14,15]. Spin-crossover complexes [16-20] are particularly interesting for such purpose, as they can exist in two stable spin states and have been largely studied. Even if spin-crossover behavior is theoretically expected to occur in octahedral complexes with $3 \mathrm{~d}^{4}$ to $3 \mathrm{~d}^{7}$ electronic configurations, most spin-crossover complexes are based on $\mathrm{Fe}(\mathrm{III}), \mathrm{Fe}(\mathrm{II})$, and $\mathrm{Co}(\mathrm{II})$, with only few reported examples of compounds of $\mathrm{Mn}(\mathrm{II}), \mathrm{Mn}(\mathrm{III}), \mathrm{Cr}(\mathrm{II})$, and $\mathrm{Co}(\mathrm{III})$. The study of spin-crossover systems has originated from $\mathrm{d}^{6} \mathrm{Fe}(\mathrm{II})$ complexes that can be reversibly switched between high spin (HS, $S=2$ ) and low spin (LS, $S=0$ ) states by using several stimuli [6,21]. The evolution of the magnetization of some Fe(II) complexes has shown a thermally induced spin crossover that is associated sometimes with a hysteresis loop (Figure 1b) [4]. The HS state, stable at high temperature, is converted to LS upon cooling. This effect has an entropic origin due to a higher number of microstate and vibrational entropy in the HS configuration [5]. Light can also be used at a low temperature to trigger a spin transition from LS to HS by a light induced excited spin state trapping (LIESST) effect (Figure 1a) [22,23]. In this case, an increase of the magnetization is observed upon irradiation at low temperature, indicating the population of the metastable HS state. However, by increasing the temperature, a drop in the magnetization is observed at temperatures where the thermal energy is enough to allow for a relaxation to the stable LS state [24]. Apart from temperature and light, chemical [25], electrical [26], or pressure [27] stimuli have also been used to induce a spin crossover.

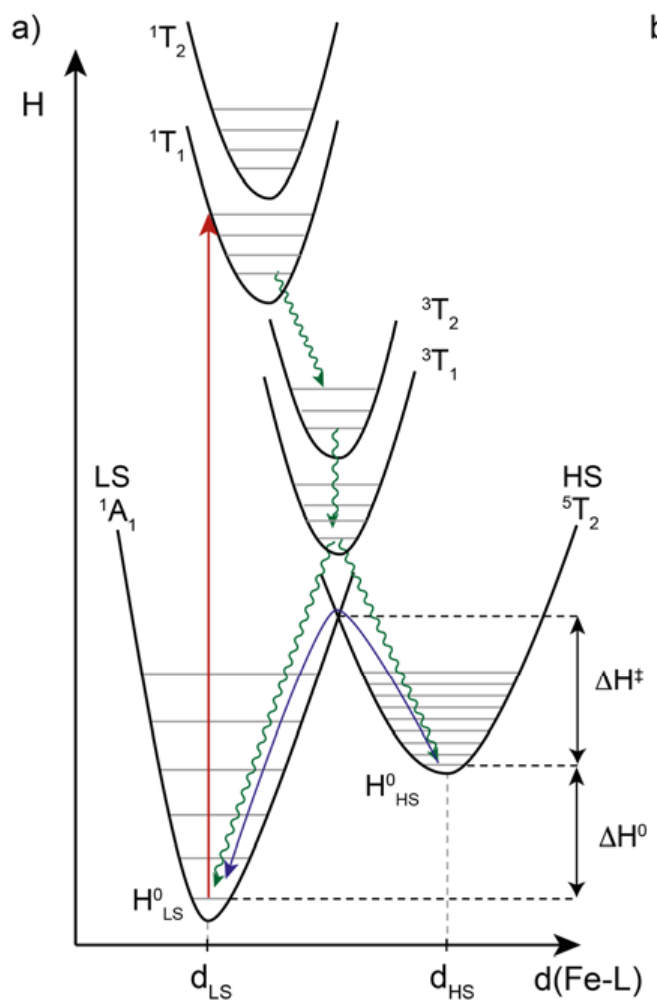

b)

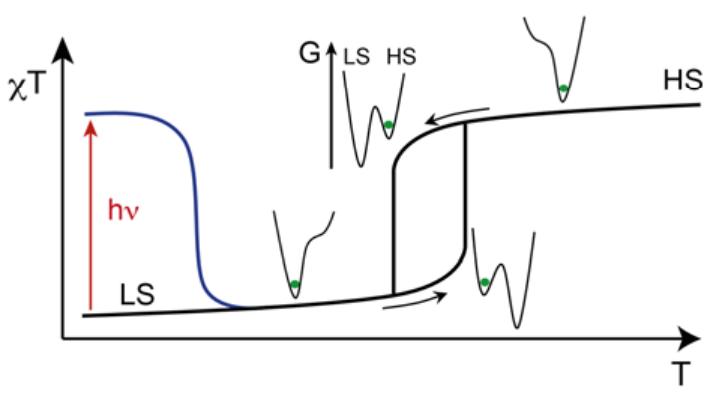

Figure 1. (a) Schematic energy diagram of high spin (HS) and low spin (LS) Fe(II) complex with light induced excited spin state trapping (LIESST) mechanism; $\Delta \mathrm{H}^{0}$ correspond to the difference in energy between HS and LS state; $\Delta \mathrm{H}^{\ddagger}$ the activation energy; $\mathrm{d}_{\mathrm{LS}}$ and $\mathrm{d}_{\mathrm{HS}}$ correspond to the metal ligand distance in the LS and HS state, respectively; $(\mathbf{b}) \chi T=\mathrm{f}(T)$ curve for spin crossover complexes showing an hysteresis loop (in black) and spin transition from LS to HS due to the LIESST effect (in blue).

Multi-metallic complexes such as Prussian-blue analogues have also attracted a wide interest as switchable systems due to the ability to switch the exchange interaction between different spin carriers connected by a bridging cyanide ligand. Light has been a choice stimulus for photo-induced electron transfer in molecular polymetallic architectures [28-30], crystals [31], or valence tautomerism complexes [32,33]. A noticeable magnetic property to switch is the Single Molecule Magnet (SMM) 
behavior. Nevertheless, to the best of our knowledge, only scarce examples have been reported showing extinction of SMM property caused by electrochemical stimulus [34-37], or photo-induced electron transfer [38].

The most common approach to switch the total spin of a molecule in spin crossover, photomagnetic [39,40], or photochromic systems, is to use a stimulus directly modifying the electronic state of the site responsible for the magnetic properties. This review is focused on magnetic switches based on a mechanical motion enabling the stimulus to be targeted on a remote site. This approach is interesting since the two processes of motion and magnetic properties change are distinguished, so that a given mechanical switch can be combined with different functional units. Three main approaches to control magnetic properties by a mechanical motion can be outlined (Figure 2): (i) modulating the ligand-field strength by a change in configuration of the ligand; (ii) changing the coordination number; and, (iii) modulating the coupling between two spin-centers. These strategies will be developed in the following sections.

a) motion-driven ligand field change

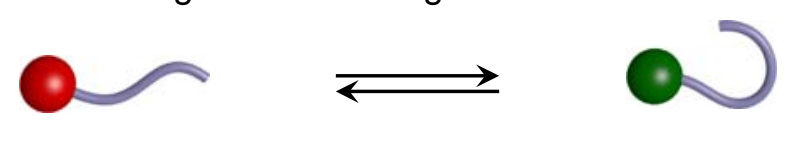

b) motion-driven coordination number change

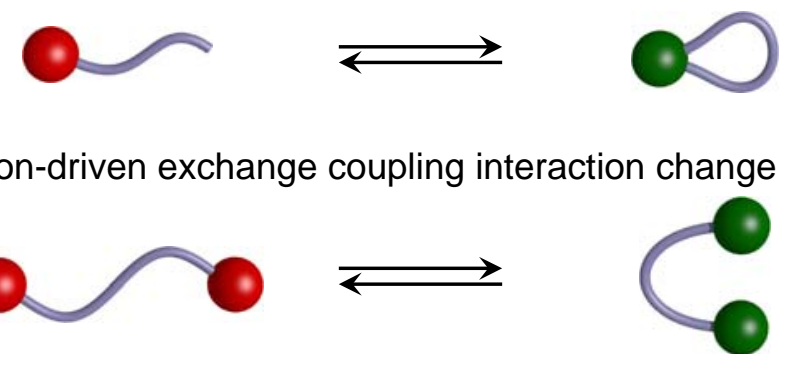

Figure 2. Main approaches to switch magnetic properties by a mechanical motion. (a) ligand-field change; (b) coordination number change; (c) exchange coupling interaction change. The spheres represent a metal cation with a given magnetic property in red or green. The ribbon represents a ligand in different configurations.

\section{Spin State Change by Ligand Field Strength Modulation}

The strategy to modulate the ligand field strength by a mechanical motion located on a ligand has been successfully applied for spin crossover complexes with isomerizable ligands by using light as a stimulus. This photomagnetic effect based on a photochemical reaction on the ligand has been called "Ligand-driven light-induced spin change" (LD-LISC) [41]. In this approach, the electronic spin state of the metal ion can be switched by means of light over a broad range of temperatures, including room temperature.

The first exemple of the LD-LISC effect was described by Zarembovich et al. in 1994 [42], with complex $\left[\mathrm{Fe}^{\mathrm{II}}(\mathrm{stpy})_{4}(\mathrm{NCS})_{2}\right]$ bearing photo-isomerizable styryl pyridine ligand (stpy) (Figure 3). [ $\mathrm{Fe}^{\mathrm{II}}$ (trans-stpy) $\left.{ }_{4}(\mathrm{NCS})_{2}\right]$ presents a spin crossover centered around $108 \mathrm{~K}$, whereas $\left[\mathrm{Fe}^{\mathrm{II}}(\text { cis-stpy })_{4}(\mathrm{NCS})_{2}\right]$ remains HS on the whole temperature range $(10-300 \mathrm{~K})$. This difference in behavior was attributed to a higher ligand field for trans vs. cis isomer. The system was further improved [43] using bidendate ligand 4-methyl-4'-trans-styryl-2,2'-bipyridine to finally obtain a LD-LISC effect at room temperature [44]. By using ligands incorporating an azobenzene unit a reversible LD-LISC effect was obtained by Nishihara (Figure 4) [45]. When compared to styryl derivatives, azo compounds present a larger difference in the absorption spectra between trans and cis isomers, which enables a selective isomerization depending on the wavelength of the irradiation. 
The LS state is stabilized by trans isomer, while HS state by cis isomer and a modest $5 \%$ change in the spin-state conversion was observed in solution in acetone at room temperature.

a)

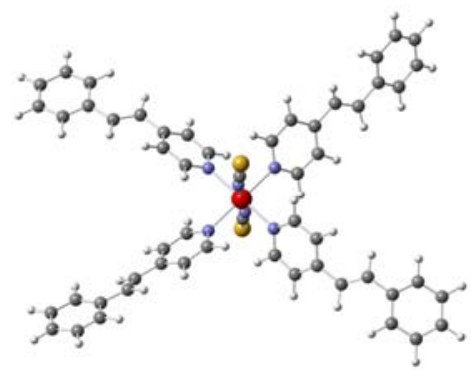

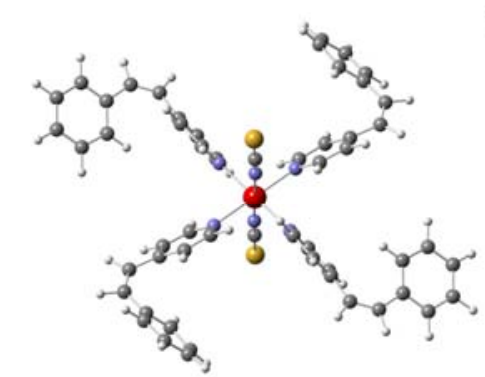

b)

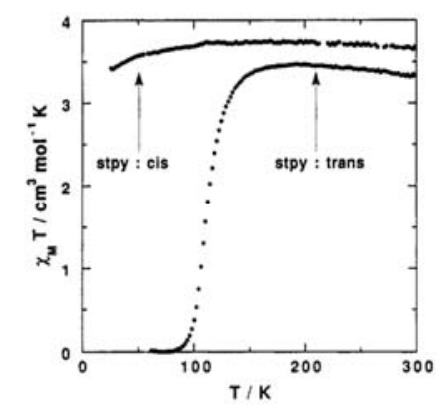

Figure 3. (a) Molecular structures for the all-E and all-Z photoisomers of the mononuclear iron(II) complex $\left[\mathrm{Fe}^{\mathrm{II}}(\text { stpy })_{4}(\mathrm{NCS})_{2}\right]$ and (b) the corresponding magnetic properties showing the thermal-induced SCO in the former case. Reprinted with permission from [42]. Copyright American Chemical Society, 1994.
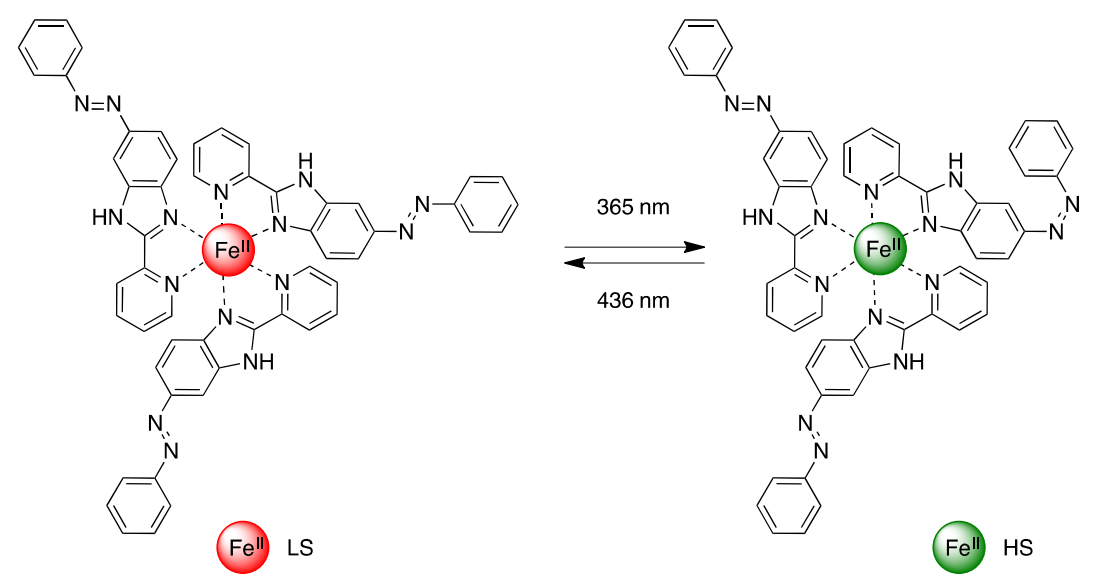

Figure 4. Fe(II) complex with azobenzene-attached ligands showing reversible magnetization change at room temperature by irradiation at two different wavelengths [45].

This approach is interesting for information storage applications, but requires a switching in the solid state, which is quite challenging due to the large reorganization that is necessary for the ligand isomerization. Incorporation of $\left.\left[\mathrm{Fe}^{\mathrm{II}} \text { (4-styrylpyridine }\right)_{4}(\mathrm{NCSe})_{2}\right]$ in a polymer thin film was achieved by Boillot et al. [46], leading to bi-directional LD-LISC, but only at $130 \mathrm{~K}$. Nishihara reported in 2011 a room temperature switch in the solid state with bis(dipyrazolylstyrylpyridine)Fe(II) complexes (Figure 5) $[47,48]$. A partial transition from HS to LS was observed by performing a cis to trans photoisomerization $(\lambda>420 \mathrm{~nm})$ of cis ligand within $\left.\left[\mathrm{Fe}^{\mathrm{II}} \text { (cis-dipyrazolylstyrylpyridine }\right)_{2}\right]\left(\mathrm{BF}_{4}\right)_{2}$, but the switching was irreversible in the solid state.

Much stronger switching effect can be achieved by using electrocyclic isomerizations of photochromic ligands that are attached directly to the coordination site. Recently Khusniyarov et al. have used a phenanthroline ligand functionalized by a photochromic diarylethene moiety in a bis(pyrazolyl)borate Fe(II) complex (Figure 6). Under UV-irradiation, the open HS form is reversibly converted (about $40 \%$ ) to a LS closed form [49,50]. In parallel, Oshio et al. studied similar compounds and showed bidirectional spin-state switching by LIESST and reverse-LIESST in the solid state and in butyronitrile solution [51]. In all of these examples of LD-LISC, the mechanical motion centered on the ligand is used to modulate its electronic properties often resulting in small changes in the ligand-field. 
Moreover, in light activated switches, the photostationary state usually limits the total conversion of the ligand, making it difficult to obtain drastic changes of the magnetic properties.

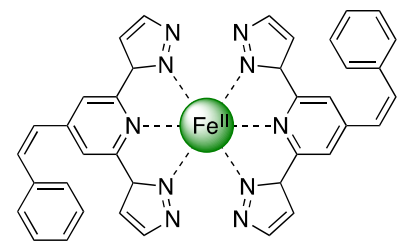

Feli) HS

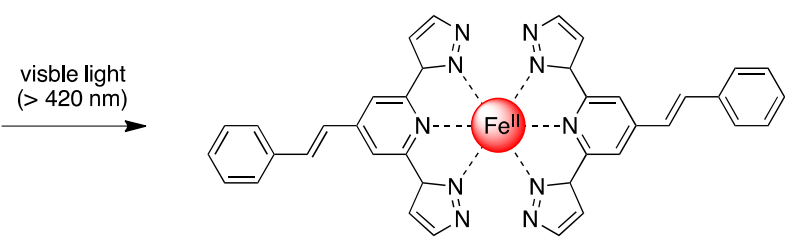

LS

Figure 5. Bis(dipyrazolylstyrylpyridine)Fe(II) complex showing irreversible switching in the solid state $[47,48]$.

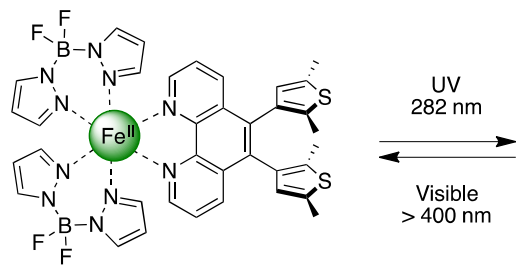

Feli) $\mathrm{HS}$

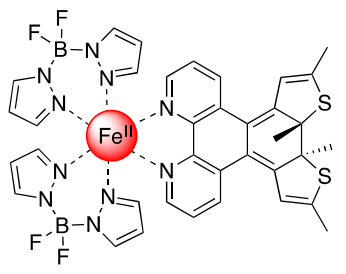

FeII) $L S$

Figure 6. Reversible photocyclization and photocycloreversion upon UV and visible light irradiation respectively for the $\mathrm{Fe}(\mathrm{II})$ complex [ $\left.\mathrm{Fe}^{\mathrm{II}}(\mathrm{btphen})(\mathrm{bpzb})_{2}\right]$ [51].

\section{Spin State Change by Coordination Number Modulation}

Recently, Herges et al. have introduced a new concept for switching the magnetic properties of homogeneous solutions at room temperature by using a light-driven ligand-induced spin-state switching (LD-CISSS). The principle is to modify the coordination number of a metallic center by the way of an isomerizable ligand. In contrast to the LD-LISC approach, where the modification in ligand field strength tends to be small and a complete switching between magnetic states is difficult to achieve, the change in coordination number can induce large ligand-field modifications. The authors focused on $\mathrm{Ni}(\mathrm{II})$-porphyrin complexes, where the $\mathrm{Ni}(\mathrm{II})$ can adopt a $\mathrm{LS}(S=0)$ square planar geometry or a HS $(S=1)$ square pyramidal pentacoordinated geometry upon coordination of an apical ligand.

In a first approach, azopyridines were used as photodissociable axial ligands to control the coordination number and concurrently the spin state of the Ni(II)-porphyrin (Figure 7) [52]. In the trans configuration, the azopyridines bind to the $\mathrm{Ni}$ as axial ligands, forming paramagnetic $\mathrm{HS}(S=1) 1: 1$ and 2:1 complexes. Upon photoisomerization to the cis configuration, the steric hindrance significantly reduces the binding constant, leading to a dissociation of the apical ligand and a diamagnetic $(S=0)$ square-planar $\mathrm{Ni}(\mathrm{II})$. By using a large excess of an azopyridine substituted in 4 and $4^{\prime}$ position with an isopropyl group, the percentage of paramagnetic Ni centers was reversibly switched between $20.5 \%$ and $68.1 \%$. In this system, the efficiency depends on the photostationary states of the ligand at the two irradiation wavelengths and the association constants of the two corresponding configurations. 
a)

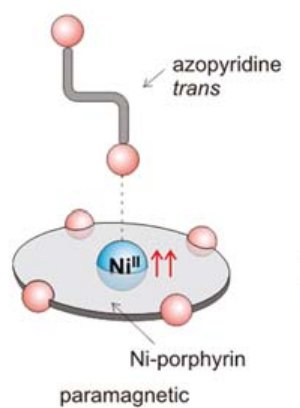

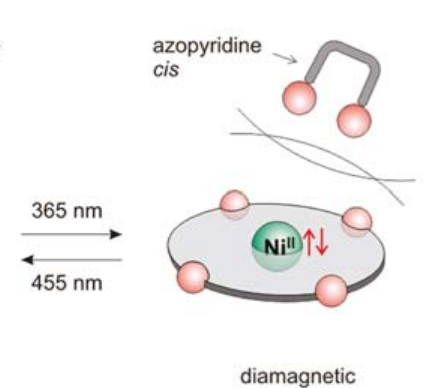

b)

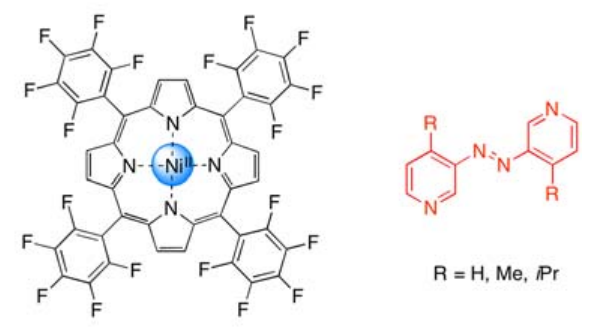

Figure 7. (a) Schematic representation of the spin-state switching of square planar Ni(II) complexes by light-induced association and dissociation of a photochromic axial ligand and (b) the corresponding $\mathrm{Ni}(\mathrm{II})$-porphyrin and azopyridine ligand. Reprinted with permission from [52]. Copyright American Chemical Society, 2011.

In order to improve the effective concentration of the ligand, a tethered azopyridine ligand to the $\mathrm{Ni}(\mathrm{II})$-porphyrin complex was used (Figure 8) [53]. In this compound, when the azopyridine is in trans configuration, the nitrogen atom of the pyridine is directed away from the Ni center, resulting in a diamagnetic LS square planar geometry. Upon irradiation by visible light at $500 \mathrm{~nm}$ the azopyridine unit isomerizes from trans to cis bringing the pendant pyridine ligand in proximity to the nickel atom. The mechanical motion thus enables a coordination of the pyridine, resulting in a pentacoordinated HS $(S=1) \mathrm{Ni}(\mathrm{II})$ in square pyramidal geometry. The reversibility of the switching was achieved by irradiation at $435 \mathrm{~nm}$ with a spin-state photo-conversion of $48 \%$ being observed in the initial design. Subsequent modifications of the system by electron-donating substituent on the pyridine moiety allowed to increase the photo-conversion rate up to $85 \%$ [54]. This work demonstrates the interest of using switchable ligands to achieve hysteresis without the need of cooperative effects, such as magnetic coupling or lattice interactions. This approach was successfully applied to obtain a photoswitchable Magnetic Resonance Imaging (MRI) contrast agent [55]. The relaxation time of the solvent protons was switched between 3.5 and $1.7 \mathrm{~s}$ improving the relaxivity of the contrast agent by a factor of 6.7. No fatigue or side reactions were observed, even after $>100,000$ switching cycles in air at room temperature showing the robustness of the system. In an extension of this work, azoimidazoles were found to exhibit higher switching efficiencies than previously described phenylazopyridine ligands [56], and were used in the tethered form for spin state switching in solution [57], as well as light responsive MRI contrast agent [58].
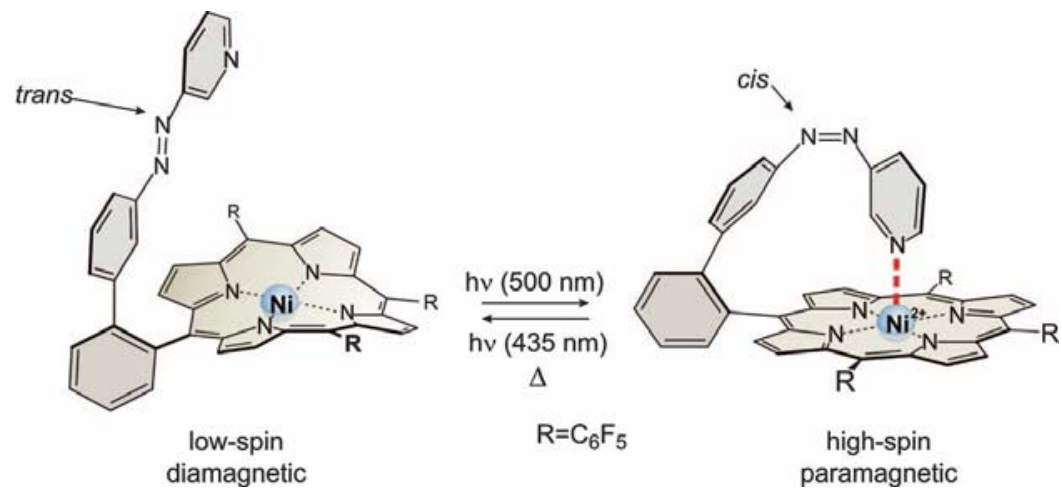

Figure 8. Photo-induced spin switch on a Ni(II)-porphyrin with tethered azo-pyridine ligand. Reprinted from [53]. Copyright American Association for the Advancement of Science, 2011.

Very recently, Weber et al. described a proton-driven coordination-induced spin state switch (PD-CISSS) of $\left[\mathrm{Fe}^{\mathrm{II}}(\text { bipy) })_{3}\right]^{2+}$ complex [59] (Figure 9). By lowering the $\mathrm{pH}, \mathrm{LS}\left[\mathrm{Fe}^{\mathrm{II}}\left(\text { bipy) }{ }_{3}\right]^{2+}\right.$ is 
protonated to form a LS $\left[\mathrm{Fe}^{\mathrm{II}}(\mathrm{bipy})_{3} \mathrm{H}\right]^{3+}$ complex that was observed by ${ }^{1} \mathrm{H}-\mathrm{NMR}$. This protonation weakens the nitrogen-iron bond, leading to a reversible bond breaking between the iron center and the protonated nitrogen of the bipy ligands, resulting in a HS pentacoordinated $\mathrm{Fe}(\mathrm{II})$ complex upon heating. In this system, the mechanical motion of the ligand is triggered by a combination of a chemical stimulus $(\mathrm{pH})$ and temperature. The effect was observed in solution and as composite materials encapsulated in the supercages of zeolite faujasite $\mathrm{NaY}$ [59].

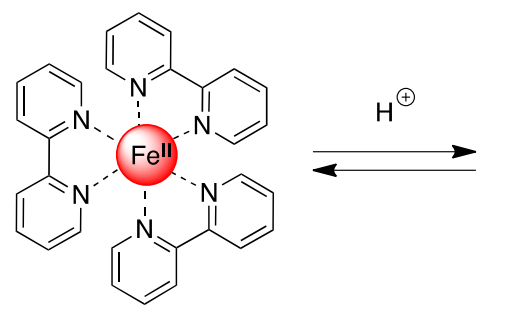

Fe'li LS

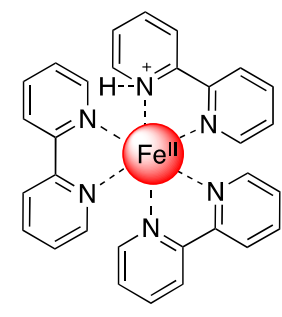

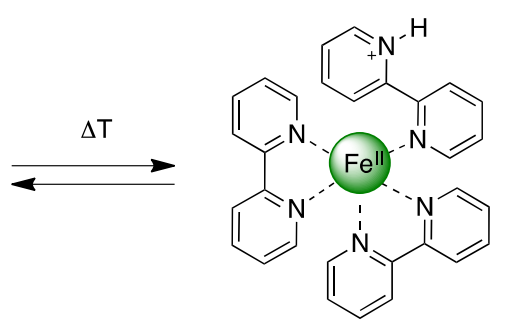

Fell HS

Figure 9. Proposed mechanism for the proton-driven coordination-induced spin state (PD-CISSS) of $\left[\mathrm{Fe}^{\mathrm{II}}(\text { bipy })_{3}\right]^{2+}[59]$.

\section{Spin State Change by Exchange Interaction Modulation}

Switching magnetic properties by modulating the coupling between two spin-centers via controlling their distance via a mechanical motion is a relatively new approach. This strategy can be coined as Ligand Driven Mechanically Induced Spin Change (LD-MISC). An early example was described by Irie et al. with a diarylethene photochromic unit substituted by two organic radicals (Figure 10) [60]. When the diarylethene unit is open, the two organic radicals are isolated. The photoinduced electrocyclization of the diarylethene moiety leads to an extended $\pi$ system, allowing for an electronic communication between the two spin carriers. An antiferromagnetic coupling is observed resulting in a modification of the total spin of the molecule. It should be noted that the spin state switch is mainly due to the change in the electronic structure of the bridging ligand and not the conformational reorganization that is induced by the closing of the photochromic unit.
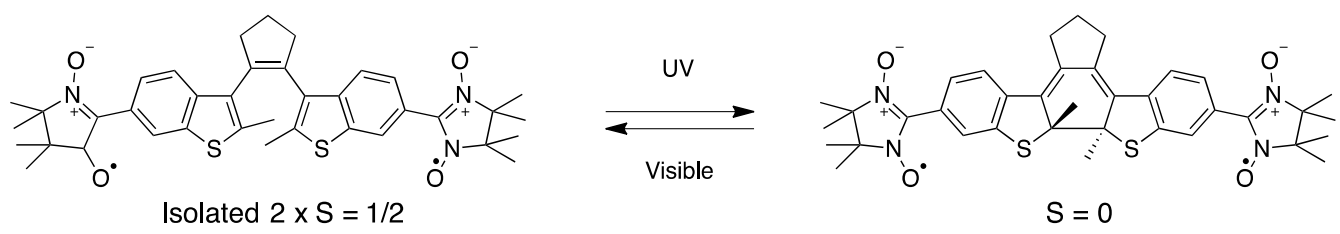

Figure 10. Photo-induced modulation of exchange coupling interaction between two radicals [60].

A similar strategy has been used by Yamashita et al. to repeatedly turn on and off the SMM (Single Molecule Magnet) behavior of two Mn(III)-salen complexes that are connected to diarylethene derivatives with two carboxyl groups (Figure 11) [61]. When the complex with the diarylethene in the closed form is converted to the open form by irradiating with visible light, slow relaxation of the magnetization was observed. This behavior, not observed for the closed form, is due to slight modifications in inter- or intra-unit $\mathrm{Mn}(\mathrm{III})-\mathrm{Mn}(\mathrm{III})$ distances upon photoisomerization. In addition, the superexchange interactions between the two $\mathrm{Mn}$ (III) ions caused by the $\pi$-conjugation of the two thiophene rings affects the magnetic properties of the two forms. In this example, the magnetic properties are interestingly activated upon irradiation with visible light. 


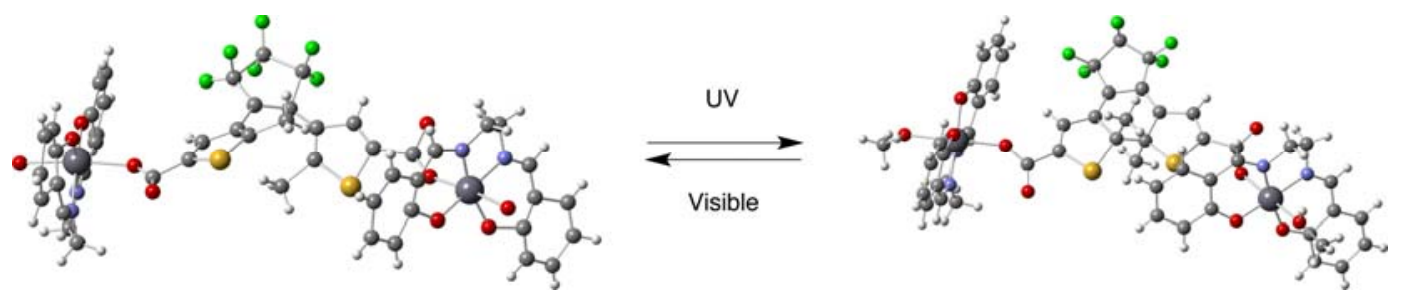

Figure 11. Switching of the Single Molecule Magnet (SMM) properties of Mn(III)-salen complexes by photoisomerization of diarylethene moiety [61].

Reversible through-space control of magnetic interaction has been described recently by Kaneko et al. using a polymer bearing organic radicals (Figure 12) [62]. Chiral diethynyl-1,1'-binaphthyl moieties were inserted in a poly(1,3-phenyleneethynylene) chain. The polymer can fold into a helicoidal conformation in basic media, bringing the radical units in spatial proximity. This proximity results in a relatively strong antiferromagnetic behavior when compared with the weak antiferromagnetic behavior of the polyradical in the unfolded conformation. This system uses a chemical stimulus $(\mathrm{pH})$ to trigger the conformational change of the polymer and the modification of the magnetic properties.

a)

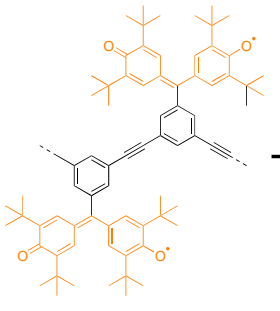

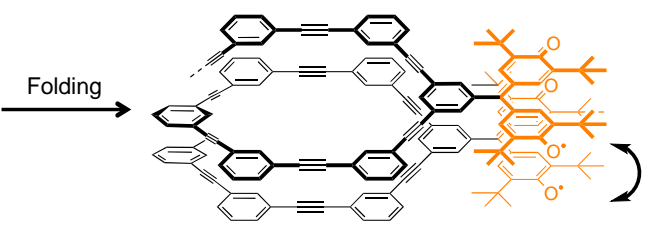

b)

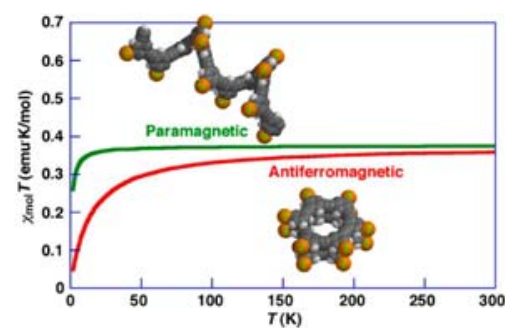

Figure 12. (a) Folding of polyradical polymer upon $\mathrm{pH}$ change; (b) $\chi T=\mathrm{f}(T)$ of unfolded (green), and folded structure (red). Reprinted with permission from [62]. Copyright American Chemical Society, 2013.

Feringa et al. [63] used the photoisomerization of an overcrowded double bond to switch the intramolecular through-space magnetic interaction between two (2,2,6,6-Tetramethylpiperidin-1-yl)oxyl (TEMPO) spin centers (Figure 13). In the trans state, the two spin centers are well separated by a distance of $\sim 22 \AA$, resulting in a non-coupled system, as shown by the three-line electron paramagnetic resonance (EPR) spectrum. Upon photoswitching, the trans form is converted to a cis conformation, where the two radicals are separated by $\sim 7 \AA$. The two spins are strongly interacting by a through space dipolar coupling, as shown from the five-line EPR spectrum. This switching is obtained at room temperature and in solution, but the conversion is limited by the photostationary state of $89 \%$ cis form.

A similar control of the interaction between two TEMPO radical moieties was recently described by Credi et al. [64] using an acid-base switchable molecular shuttle (Figure 14). The shuttle is based on a [2]rotaxane, bearing stable TEMPO radical units on the ring and on the side of the axle. The ring is located on the dialkylammonium station when it is protonated, resulting in non-coupled radicals with a characteristic three-line EPR spectrum. Upon deprotonation, the ring moves to the bispyridinium site and the two radicals become coupled by through space dipolar interaction, as observed from the five-line EPR spectrum. The process is reversible, and was repeated six times, highlighting the stability of the system. Thus the mechanical motion of the ring triggered by a chemical stimulus $(\mathrm{pH})$ in this molecular machine enables a reversible on/off switching of magnetic interactions. 
a)
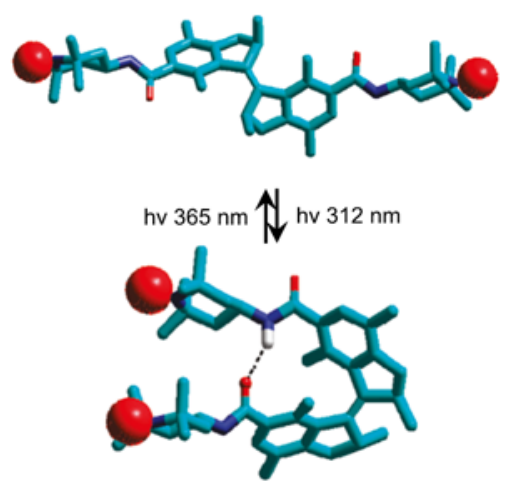

b)
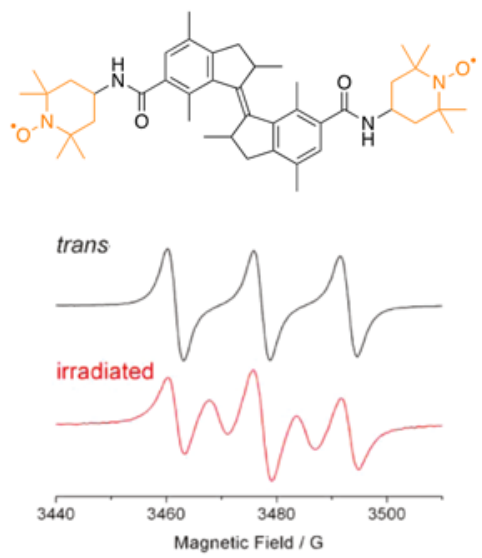

Figure 13. (a) Photo-induced mechanical switch of through space dipolar interaction by a molecular motor scaffold; (b) EPR spectra of trans (black) and cis form after irradiation at $312 \mathrm{~nm}$ (red). Reprinted with permission from [63]. Copyright American Chemical Society, 2011.

a)

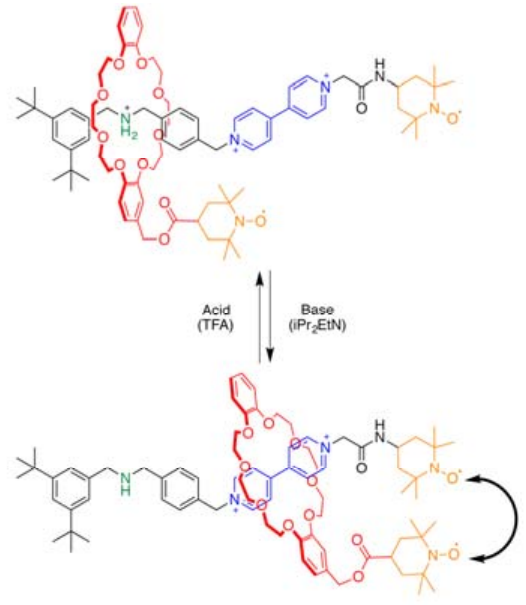

b)

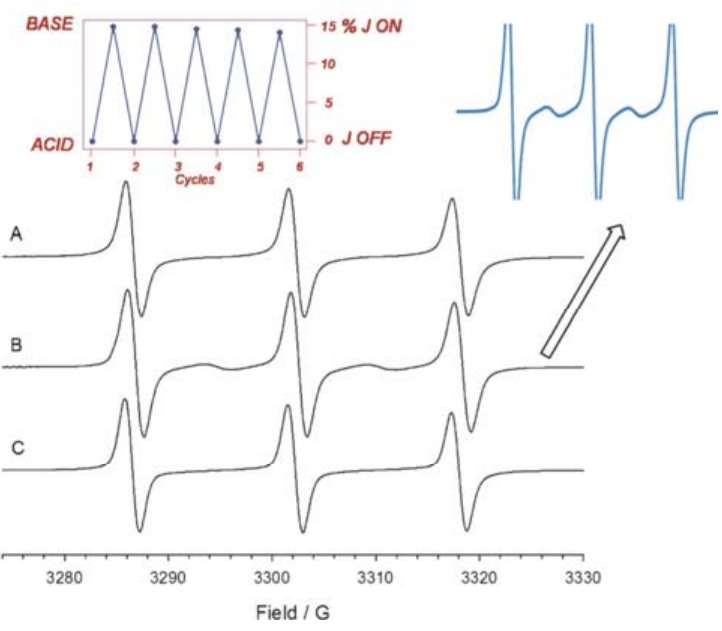

Figure 14. (a) $\mathrm{pH}$-induced mechanical switch of through space dipolar interaction by a [2]rotaxane; (b) EPR spectra before (A) and after sequential addition of 2 equiv. of $i \operatorname{Pr}_{2} \mathrm{EtN}(\mathrm{B})$ and $\mathrm{CF}_{3} \mathrm{COOH}(\mathrm{C})$. Reproduced from [64]. Copyright WILEY-VCH Verlag GmbH\&Co. KGaA, 2015.

Coordination-based switches are attractive as they present benefits over photochemical switches, by enabling total conversion and offering thermal stability. We have recently developed switchable molecular tweezers $[65,66]$, which are based on a terpyridine ligand substituted by metal-salphen complexes that can switch upon metal coordination from a " $\mathrm{W}$ " shaped open form to a " $\mathrm{U}$ " closed form bringing the two salphen moieties in close spatial proximity (Figure 15). We have used this modular design to control the magnetic interaction between paramagnetic $\mathrm{Cu}(\mathrm{II})$-salphen $\left(\mathrm{d}^{9} S=1 / 2\right)$ complexes via a mechanical motion [67]. Upon zinc coordination to the terpy moiety, conversion from the open to the closed conformation was obtained. The reversible re-opening was achieved by the addition of a competitive ligand. Crystallographic structures showed a considerable modification of the distance between the two $\mathrm{Cu}$ (II) ions (from 21 to $4 \AA$ ) induced by the mechanical motion (Figure 15). Each $\mathrm{Cu}$ (II) presents a spin $S=1 / 2$, and is isolated in the open form, as demonstrated by the characteristic EPR signal. In the closed form, intramolecular through space dipolar interactions were observed by EPR with doublet-like signal expected for a triplet state. Superconducting Quantum Interference Device (SQUID) measurements have shown an antiferromagnetic exchange interaction in the closed form, with a $J=-1.4 \mathrm{~cm}^{-1}$ value that is typical of through space exchange interaction. Thus, the control of the exchange interaction between two paramagnetic centers was achieved in solution by using 
a mechanical motion. Upon tweezers closing the two isolated $\frac{1}{2}$ spins located on each $\mathrm{Cu}$ (II) become antiferromagnetically coupled through space, leading to a singlet ground state. This system is a rare example of mechano-induced modification of magnetic properties offering quantitative conversion between both states that are stable at room temperature.

a)

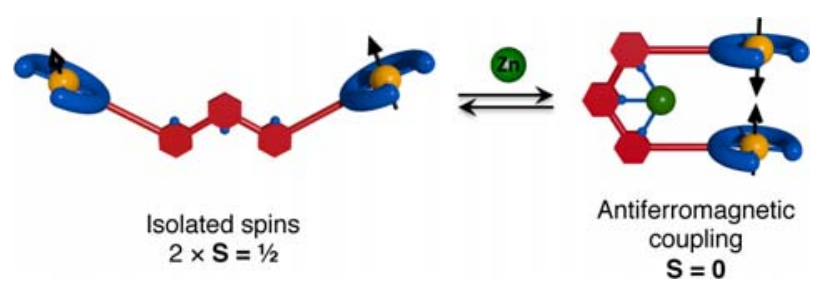

b)
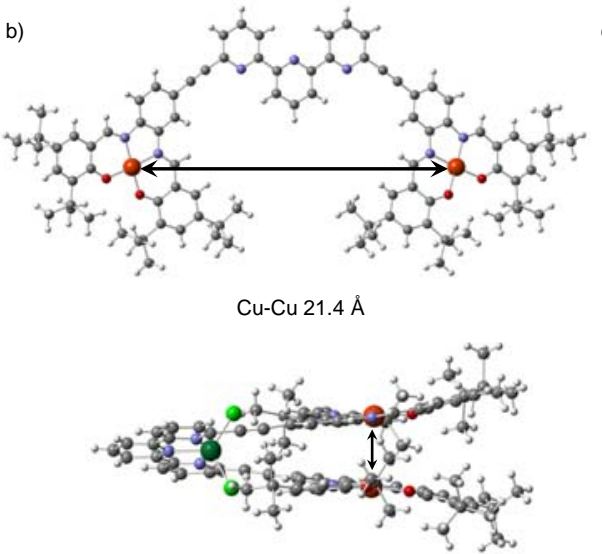

Cu-Cu $4.03 \AA$
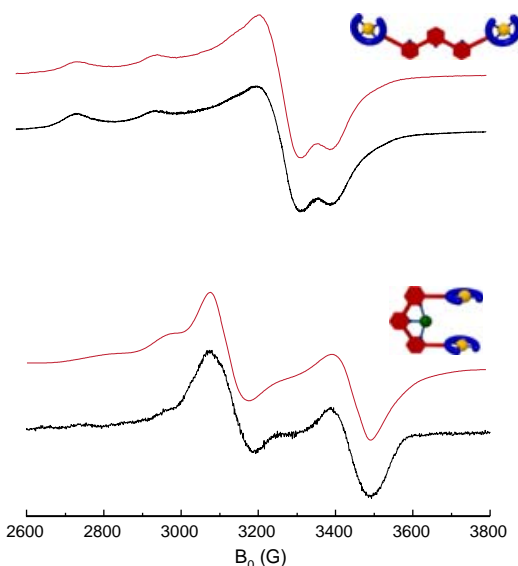

Figure 15. (a) Principle of the control of the exchange interaction between two paramagnetic centers by using the mechanical motion of switchable molecular tweezers; (b) Crystal structure of open and closed terpy(Cu-salphen $)_{2}$ tweezers and (c) corresponding EPR spectra in frozen solution showing a signal characteristic of isolated $2 \times S=1 / 2$ spins in the open form, and a doublet signal corresponding to $S=1$ system resulting from dipolar interaction between the two $\mathrm{Cu}(\mathrm{II})$ in the closed form. Adapted from [67] with the permission of The Royal Society of Chemistry.

The modularity of our platform was then exploited to combine ion-triggered mechanical motion with redox activity in order to achieve a multi-state switch [68]. Ni(II)-salen complexes were chosen as functional units since they are known to be redox non-innocent with reversible oxidation properties and valence tautomerism between $\mathrm{Ni}^{\mathrm{III}}$-salen and $\mathrm{Ni}^{\mathrm{II}}$-salen ${ }^{+}$species. A six level switch was obtained by combining three orthogonal stimuli (Figure 16): (i) metal coordination of the terpyridine moiety to open/close the tweezers; (ii) reversible oxidation of the Ni-salen complexes; and, (iii) guest binding to oxidized Ni-salen coupled to valence-tautomerism. The metal coordination stimulus (axis a) enables a mechanical closing of the neutral and oxidized open states (edges a, a', a'). The switching along theses edges is reversible upon addition of a competitive ligand, such as tren or terpyridine. The orthogonal redox stimulus (axis $\mathbf{b}$ ) triggers a reversible oxidation of the open or closed tweezers adding two new accessible states along edge $b$ and $b^{\prime}$. Finally, the pyrazine binding stimulus (axis c) enabled two new states that were accessible from the oxidized species along edge $c$ and $c^{\prime}$. The coordination of the pyrazine ligand in the oxidized state has a drastic effect on the electronic properties of the system by shifting the radical location from $\mathrm{Ni}^{\mathrm{II}}$-phenoxyl to $\mathrm{Ni}^{\mathrm{III}}$-phenoxide as monitored by EPR (Figure 16b). In the open form the two spins located on the $\mathrm{Ni}(\mathrm{III})$ are isolated. Upon closing by coordination, a through ligand magnetic coupling is obtained between the two Ni(III) centers by a bridging pyrazine ligand, as observed by EPR with a $S=1$ system. This multi-functional system combines mechanical motion with redox-activity to change magnetic properties in a six-state system that is accessible by three orthogonal stimuli. 
a)

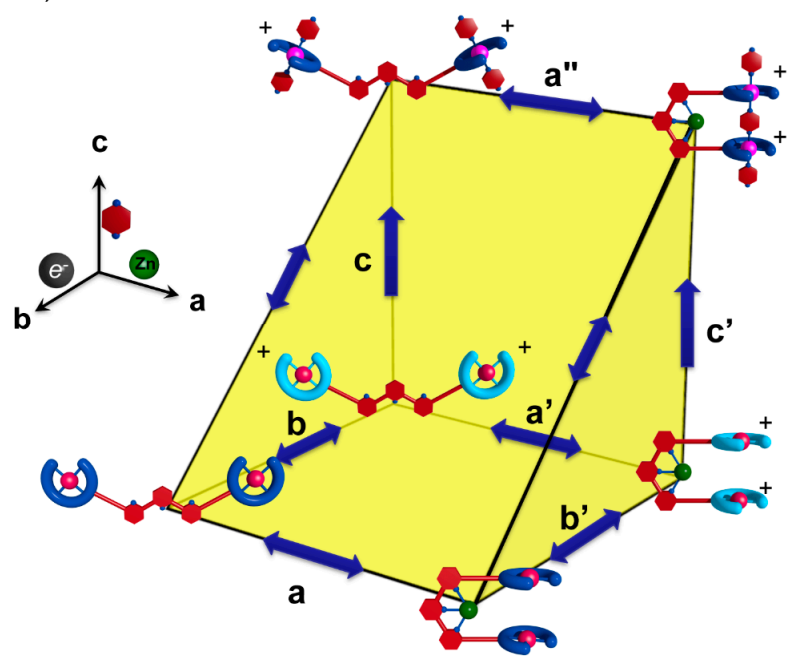

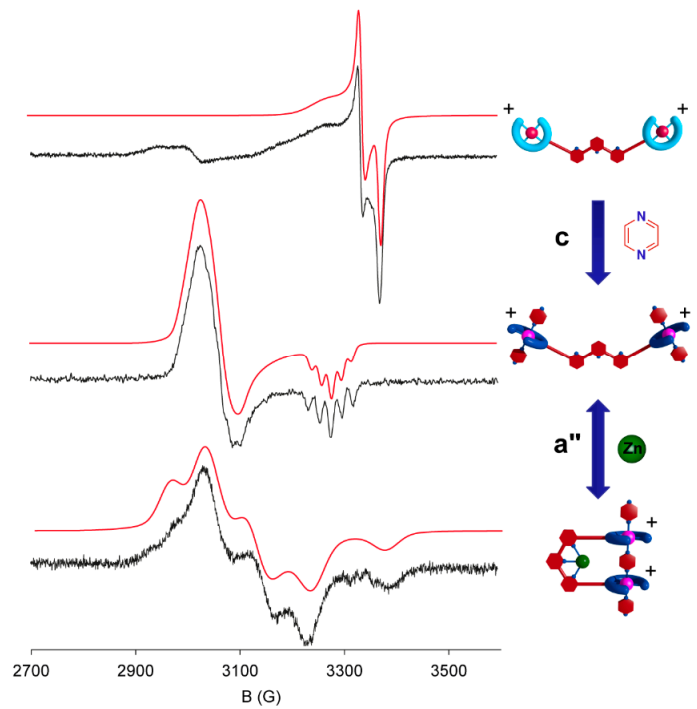

Figure 16. (a) Six-states mechanical switch with valence tautomerism and magnetic interaction control by a bridging ligand; (b) Evolution of EPR spectra upon oxidation, valence tautomerism and bridging ligand intercalation. Reprinted with permission from [68]. Copyright American Chemical Society, 2017.

\section{Summary and Outlook}

In this review, we have outlined the different approaches using mechanical motion to switch magnetic properties. The first reported one is based on a modification of the ligand field strength by a configurational change that was successfully applied in SCO complexes. However, the electronic modifications resulting from the motion are usually weak, resulting in limited changes of the magnetic properties. The development of supramolecular approaches to control the coordination sphere or the interaction between spin carriers has resulted in a renewal of the field with larger effects being achievable. Despite the fact that the synthesis of complex architectures becomes more challenging and requires the development of more sophisticated theoretical models, these strategies are attractive as they do not rely on intermolecular interactions and enable switching at the single molecule level. Potential application can be envisaged for the elaboration of, among others, smart MRI contrast agents, molecular actuator devices [69], molecular spintronics [70], and quantum computing devices [71]. However future challenges remain in the surface deposition of such systems as thin films, self- assembled monolayers, or even at the single molecule level. The recent development of new physics instruments, such as the nano-SQUID, which enables the study of magnetic properties at the single-molecule level are encouraging and should open new perspectives. While most systems are based on light stimulus, the electric control of the spin state should be more developed, as it is crucial for spintronics applications and is currently limited. Finally, the integration of the concepts of mechanical motion with other properties, such as SMM, luminescence, or chirality are investigated to obtain multifunctional systems [72], which could lead, for example, to optoelectronic devices.

Acknowledgments: Financial support from the ANR JCJC SMARTEES (15-CE07-0006-01) is acknowledged.

Conflicts of Interest: The authors declare no conflict of interest.

\section{References}

1. Balzani, V.; Venturi, M.; Credi, A. Molecular Devices and Machines: Concepts and Perspectives for the Nanoworld; Wiley-VCH: Weinheim, Germany, 2008.

2. Kay, E.R.; Leigh, D.A. Rise of the Molecular Machines. Angew. Chem. Int. Ed. 2015, 54, 10080-10088. [CrossRef] [PubMed] 
3. Sato, O.; Tao, J.; Zhang, Y.-Z. Control of Magnetic Properties through External Stimuli. Angew. Chem. Int. Ed. 2007, 46, 2152-2187. [CrossRef] [PubMed]

4. Gutlich, P.; Garcia, Y.; Goodwin, H.A. Spin crossover phenomena in Fe(II) complexes. Chem. Soc. Rev. 2000, 29, 419-427. [CrossRef]

5. Gütlich, P.; Hauser, A.; Spiering, H. Thermal and Optical Switching of Iron(II) Complexes. Angew. Chem. Int. Ed. 1994, 33, 2024-2054. [CrossRef]

6. Bonnet, S.; Molnár, G.; Sanchez Costa, J.; Siegler, M.A.; Spek, A.L.; Bousseksou, A.; Fu, W.-T.; Gamez, P.; Reedijk, J. Influence of Sample Preparation, Temperature, Light, and Pressure on the Two-Step Spin Crossover Mononuclear Compound [Fe(bapbpy)(NCS)2]. Chem. Mater. 2009, 21, 1123-1136. [CrossRef]

7. Bousseksou, A.; Molnár, G.; Matouzenko, G. Switching of Molecular Spin States in Inorganic Complexes by Temperature, Pressure, Magnetic Field and Light: Towards Molecular Devices. Eur. J. Inorg. Chem. 2004, 4353-4369. [CrossRef]

8. Real, J.A.; Gaspar, A.B.; Munoz, M.C. Thermal, pressure and light switchable spin-crossover materials. Dalton Trans. 2005, 2062-2079. [CrossRef] [PubMed]

9. Halcrow, M.A. Structure: Function relationships in molecular spin-crossover complexes. Chem. Soc. Rev. 2011, 40, 4119-4142. [CrossRef] [PubMed]

10. Halcrow, M. The Effect of Ligand Design on Metal Ion Spin State-Lessons from Spin Crossover Complexes. Crystals 2016, 6, 58. [CrossRef]

11. Senthil Kumar, K.; Ruben, M. Emerging trends in spin crossover (SCO) based functional materials and devices. Coord. Chem. Rev. 2017, 346, 176-205. [CrossRef]

12. Sato, O. Photoinduced magnetization in molecular compounds. J. Photochem. Photobiol. C 2004, 5, $203-223$. [CrossRef]

13. Bleuzen, A.; Marvaud, V.; Mathoniere, C.; Sieklucka, B.; Verdaguer, M. Photomagnetism in Clusters and Extended Molecule-Based Magnets. Inorg. Chem. 2009, 48, 3453-3466. [CrossRef] [PubMed]

14. Gatteschi, D.; Sessoli, R. Quantum Tunneling of Magnetization and Related Phenomena in Molecular Materials. Angew. Chem. Int. Ed. 2003, 42, 268-297. [CrossRef] [PubMed]

15. Sessoli, R.; Powell, A.K. Strategies towards single molecule magnets based on lanthanide ions. Coord. Chem. Rev. 2009, 253, 2328-2341. [CrossRef]

16. Brooker, S. Spin crossover with thermal hysteresis: Practicalities and lessons learnt. Chem. Soc. Rev. 2015, 44, 2880-2892. [CrossRef] [PubMed]

17. Gaspar, A.B.; Seredyuk, M. Spin crossover in soft matter. Coord. Chem. Rev. 2014, 268, 41-58. [CrossRef]

18. Gütlich, P.; Gaspar, A.B.; Garcia, Y. Spin state switching in iron coordination compounds. Beilstein J. Org. Chem. 2013, 9, 342-391. [CrossRef] [PubMed]

19. Bousseksou, A.; Molnar, G.; Salmon, L.; Nicolazzi, W. Molecular spin crossover phenomenon: Recent achievements and prospects. Chem. Soc. Rev. 2011, 40, 3313-3335. [CrossRef] [PubMed]

20. Khusniyarov, M.M. How to Switch Spin-Crossover Metal Complexes at Constant Room Temperature. Chem. Eur. J. 2016, 22, 15178-15191. [CrossRef] [PubMed]

21. Craig, G.A.; Costa, J.S.; Roubeau, O.; Teat, S.J.; Shepherd, H.J.; Lopes, M.; Molnar, G.; Bousseksou, A.; Aromi, G. High-temperature photo-induced switching and pressure-induced transition in a cooperative molecular spin-crossover material. Dalton Trans. 2014, 43, 729-737. [CrossRef] [PubMed]

22. Hauser, A. Light-Induced Spin Crossover and the High-Spin Low-Spin Relaxation. In Spin Crossover in Transition Metal Compounds II; Springer: Berlin/Heidelberg, Germany, 2004; Volume 234; pp. 155-198.

23. Unruh, D.; Homenya, P.; Kumar, M.; Sindelar, R.; Garcia, Y.; Renz, F. Spin state switching of metal complexes by visible light or hard X-rays. Dalton Trans. 2016, 45, 14008-14018. [CrossRef] [PubMed]

24. Mondal, A.; Li, Y.; Chamoreau, L.M.; Seuleiman, M.; Rechignat, L.; Bousseksou, A.; Boillot, M.L.; Lescouezec, R. Photo- and thermo-induced spin crossover in a cyanide-bridged $\{\mathrm{Mo}(\mathrm{V}) 2 \mathrm{Fe}(\mathrm{II}) 2\}$ rhombus molecule. Chem. Commun. 2014, 50, 2893-2895. [CrossRef] [PubMed]

25. Halder, G.J.; Cameron, J.K.; Moubaraki, B.; Murray, K.S.; Cashion, J.D. Guest-Dependent Spin Crossover in a Nanoporous Molecular Framework Material. Science 2002, 298, 1762-1765. [CrossRef] [PubMed]

26. Mahfoud, T.; Molnár, G.; Bonhommeau, S.; Cobo, S.; Salmon, L.; Demont, P.; Tokoro, H.; Ohkoshi, S.; Boukheddaden, K.; Bousseksou, A. Electric-Field-Induced Charge-Transfer Phase Transition: A Promising Approach Toward Electrically Switchable Devices. J. Am. Chem. Soc. 2009, 131, 15049-15054. [CrossRef] [PubMed] 
27. Coronado, E.; Giménez-López, M.C.; Levchenko, G.; Romero, F.M.; García-Baonza, V.; Milner, A.; Paz-Pasternak, M. Pressure-Tuning of Magnetism and Linkage Isomerism in Iron(II) Hexacyanochromate. J. Am. Chem. Soc. 2005, 127, 4580-4581. [CrossRef] [PubMed]

28. Herrera, J.M.; Marvaud, V.; Verdaguer, M.; Marrot, J.; Kalisz, M.; Mathonière, C. Reversible Photoinduced Magnetic Properties in the Heptanuclear Complex [MoIV(CN)2(CNCuL)6]8+: A Photomagnetic High-Spin Molecule. Angew. Chem. Int. Ed. 2004, 43, 5468-5471. [CrossRef] [PubMed]

29. Hilfiger, M.G.; Chen, M.; Brinzari, T.V.; Nocera, T.M.; Shatruk, M.; Petasis, D.T.; Musfeldt, J.L.; Achim, C.; Dunbar, K.R. An Unprecedented Charge Transfer Induced Spin Transition in an Fe-Os Cluster. Angew. Chem. Int. Ed. 2010, 49, 1410-1413. [CrossRef] [PubMed]

30. Mondal, A.; Chamoreau, L.-M.; Li, Y.; Journaux, Y.; Seuleiman, M.; Lescouëzec, R. WCo Discrete Complex Exhibiting Photo- and Thermo-Induced Magnetisation. Chem. Eur. J. 2013, 19, 7682-7685. [CrossRef] [PubMed]

31. Hozumi, T.; Hashimoto, K.; Ohkoshi, S.-I. Electrochemical Synthesis, Crystal Structure, and Photomagnetic Properties of a Three-Dimensional Cyano-Bridged Copper-Molybdenum Complex. J. Am. Chem. Soc. 2005, 127, 3864-3869. [CrossRef] [PubMed]

32. Gu, Z.Z.; Sato, O.; Iyoda, T.; Hashimoto, K.; Fujishima, A. Spin Switching Effect in Nickel Nitroprusside: Design of a Molecular Spin Device Based on Spin Exchange Interaction. Chem. Mater. 1997, 9, 1092-1097. [CrossRef]

33. Adams, D.M.; Hendrickson, D.N. Pulsed Laser Photolysis and Thermodynamics Studies of Intramolecular Electron Transfer in Valence Tautomeric Cobalt o-Quinone Complexes. J. Am. Chem. Soc. 1996, 118, 11515-11528. [CrossRef]

34. Freedman, D.E.; Jenkins, D.M.; Iavarone, A.T.; Long, J.R. A Redox-Switchable Single-Molecule Magnet Incorporating [Re(CN)7]3. J. Am. Chem. Soc. 2008, 130, 2884-2885. [CrossRef] [PubMed]

35. Norel, L.; Bernot, K.; Feng, M.; Roisnel, T.; Caneschi, A.; Sessoli, R.; Rigaut, S. A carbon-rich ruthenium decorated dysprosium single molecule magnet. Chem. Commun. 2012, 48, 3948-3950. [CrossRef] [PubMed]

36. Norel, L.; Feng, M.; Bernot, K.; Roisnel, T.; Guizouarn, T.; Costuas, K.; Rigaut, S. Redox Modulation of Magnetic Slow Relaxation in a 4f-Based Single-Molecule Magnet with a 4d Carbon-Rich Ligand. Inorg. Chem. 2014, 53, 2361-2363. [CrossRef] [PubMed]

37. Fortier, S.; Le Roy, J.J.; Chen, C.-H.; Vieru, V.; Murugesu, M.; Chibotaru, L.F.; Mindiola, D.J.; Caulton, K.G. A Dinuclear Cobalt Complex Featuring Unprecedented Anodic and Cathodic Redox Switches for Single-Molecule Magnet Activity. J. Am. Chem. Soc. 2013, 135, 14670-14678. [CrossRef] [PubMed]

38. Nihei, M.; Okamoto, Y.; Sekine, Y.; Hoshino, N.; Shiga, T.; Liu, I.P.-C.; Oshio, H. A Light-Induced Phase Exhibiting Slow Magnetic Relaxation in a Cyanide-Bridged $\left[\mathrm{Fe}_{4} \mathrm{Co}_{2}\right]$ Complex. Angew. Chem. Int. Ed. 2012, 51, 6361-6364. [CrossRef] [PubMed]

39. Sato, O. Optically Switchable Molecular Solids: Photoinduced Spin-Crossover, Photochromism, and Photoinduced Magnetization. Acc. Chem. Res. 2003, 36, 692-700. [CrossRef] [PubMed]

40. Ohkoshi, S.; Tokoro, H. Photomagnetism in Cyano-Bridged Bimetal Assemblies. Acc. Chem. Res. 2012, 45, 1749-1758. [CrossRef] [PubMed]

41. Boillot, M.-L.; Zarembowitch, J.; Sour, A. Ligand-driven light-induced spin change (LD-LISC): A promising photomagnetic effect. Top. Curr. Chem. 2004, 234, 261-276.

42. Roux, C.; Zarembowitch, J.; Gallois, B.; Granier, T.; Claude, R. Toward Ligand-Driven Light-Induced Spin Changing. Influence of the Configuration of 4 Styrylpyridine (stpy) on the Magnetic Properties of FeII(stpy)4(NCS)2 Complexes. Crystal Structures of the Spin-Crossover Species Fe(trans-stpy)4(NCS)2 and of the High-Spin Species Fe(cis-stpy)4(NCS)2. Inorg. Chem. 1994, 33, 2273-2279.

43. Boillot, M.-L.; Roux, C.; Audière, J.-P.; Dausse, A.; Zarembowitch, J. Ligand-Driven Light-Induced Spin Change in Transition-Metal Complexes: Selection of an Appropriate System and First Evidence of the Effect, in FeII(4-styrylpyridine)4(NCBPh3)2. Inorg. Chem. 1996, 35, 3975-3980. [CrossRef] [PubMed]

44. Boillot, M.-L.; Chantraine, S.; Zarembowitch, J.; Lallemand, J.-Y.; Prunet, J. First ligand-driven light-induced spin change atroomtemperature in a transition-metal molecular compound. New J. Chem. 1999, 23, 179-184. [CrossRef]

45. Hasegawa, Y.; Kume, S.; Nishihara, H. Reversible light-induced magnetization change in an azobenzene-attached pyridylbenzimidazole complex of iron(II) at room temperature. Dalton Trans. 2009, 280-284. [CrossRef] [PubMed] 
46. Boillot, M.L.; Pillet, S.; Tissot, A.; Rivière, E.; Claiser, N.; Lecomte, C. Ligand-Driven Light-Induced Spin Change Activity and Bidirectional Photomagnetism of Styrylpyridine Iron(II) Complexes in Polymeric Media. Inorg. Chem. 2009, 48, 4729-4736. [CrossRef] [PubMed]

47. Takahashi, K.; Hasegawa, Y.; Sakamoto, R.; Nishikawa, M.; Kume, S.; Nishibori, E.; Nishihara, H. Solid-State Ligand-Driven Light-Induced Spin Change at Ambient Temperatures in Bis(dipyrazolylstyrylpyridine)iron(II) Complexes. Inorg. Chem. 2012, 51, 5188-5198. [CrossRef] [PubMed]

48. Hasegawa, Y.; Takahashi, K.; Kume, S.; Nishihara, H. Complete solid state photoisomerization of bis(dipyrazolylstyrylpyridine)iron(II) to change magnetic properties. Chem. Commun. 2011, 47, 6846-6848. [CrossRef] [PubMed]

49. Rösner, B.; Milek, M.; Witt, A.; Gobaut, B.; Torelli, P.; Fink, R.H.; Khusniyarov, M.M. Reversible Photoswitching of a Spin-Crossover Molecular Complex in the Solid State at Room Temperature. Angew. Chem. Int. Ed. 2015, 54, 12976-12980. [CrossRef] [PubMed]

50. Milek, M.; Heinemann, F.W.; Khusniyarov, M.M. Spin Crossover Meets Diarylethenes: Efficient Photoswitching of Magnetic Properties in Solution at Room Temperature. Inorg. Chem. 2013, 52, 11585-11592. [CrossRef] [PubMed]

51. Nihei, M.; Suzuki, Y.; Kimura, N.; Kera, Y.; Oshio, H. Bidirectional Photomagnetic Conversions in a Spin-Crossover Complex with a Diarylethene Moiety. Chem. Eur. J. 2013, 19, 6946-6949. [CrossRef] [PubMed]

52. Thies, S.; Sell, H.; Schütt, C.; Bornholdt, C.; Näther, C.; Tuczek, F.; Herges, R. Light-Induced Spin Change by Photodissociable External Ligands: A New Principle for Magnetic Switching of Molecules. J. Am. Chem. Soc. 2011, 133, 16243-16250. [CrossRef] [PubMed]

53. Venkataramani, S.; Jana, U.; Dommaschk, M.; Sonnichsen, F.D.; Tuczek, F.; Herges, R. Magnetic bistability of molecules in homogeneous solution at room temperature. Science 2011, 331, 445-448. [CrossRef] [PubMed]

54. Dommaschk, M.; Schutt, C.; Venkataramani, S.; Jana, U.; Nather, C.; Sonnichsen, F.D.; Herges, R. Rational design of a room temperature molecular spin switch. The light-driven coordination induced spin state switch (LD-CISSS) approach. Dalton Trans. 2014, 43, 17395-17405. [CrossRef] [PubMed]

55. Dommaschk, M.; Peters, M.; Gutzeit, F.; Schütt, C.; Näther, C.; Sönnichsen, F.D.; Tiwari, S.; Riedel, C.; Boretius, S.; Herges, R. Photoswitchable Magnetic Resonance Imaging Contrast by Improved Light-Driven Coordination-Induced Spin State Switch. J. Am. Chem. Soc. 2015, 137, 7552-7555. [CrossRef] [PubMed]

56. Schütt, C.; Heitmann, G.; Wendler, T.; Krahwinkel, B.; Herges, R. Design and Synthesis of Photodissociable Ligands Based on Azoimidazoles for Light-Driven Coordination-Induced Spin State Switching in Homogeneous Solution. J. Org. Chem. 2016, 81, 1206-1215. [CrossRef] [PubMed]

57. Heitmann, G.; Schütt, C.; Herges, R. Spin State Switching in Solution with an Azoimidazole-Functionalized Nickel(II)-Porphyrin. Eur. J. Org. Chem. 2016, 2016, 3817-3823. [CrossRef]

58. Heitmann, G.; Schutt, C.; Grobner, J.; Huber, L.; Herges, R. Azoimidazole functionalized Ni-porphyrins for molecular spin switching and light responsive MRI contrast agents. Dalton Trans. 2016, 45, 11407-11412. [CrossRef] [PubMed]

59. Nowak, R.; Prasetyanto, E.A.; De Cola, L.; Bojer, B.; Siegel, R.; Senker, J.; Rossler, E.; Weber, B. Proton-driven coordination-induced spin state switch (PD-CISSS) of Iron(II) complexes. Chem. Commun. 2017, 53, 971-974. [CrossRef] [PubMed]

60. Matsuda, K.; Irie, M. A Diarylethene with Two Nitronyl Nitroxides: Photoswitching of Intramolecular Magnetic Interaction. J. Am. Chem. Soc. 2000, 122, 7195-7201. [CrossRef]

61. Fetoh, A.; Cosquer, G.; Morimoto, M.; Irie, M.; El-Gammal, O.; El-Reash, G.A.; Breedlove, B.K.; Yamashita, M. Photo-activation of Single Molecule Magnet Behavior in a Manganese-based Complex. Sci. Rep. 2016, 6, 23785. [CrossRef] [PubMed]

62. Kaneko, T.; Abe, H.; Teraguchi, M.; Aoki, T. Folding-Induced Through-Space Magnetic Interaction of Poly(1,3-phenyleneethynylene)-Based Polyradicals. Macromolecules 2013, 46, 2583-2589. [CrossRef]

63. Wang, J.; Hou, L.; Browne, W.R.; Feringa, B.L. Photoswitchable intramolecular through-space magnetic interaction. J. Am. Chem. Soc. 2011, 133, 8162-8164. [CrossRef] [PubMed]

64. Bleve, V.; Schäfer, C.; Franchi, P.; Silvi, S.; Mezzina, E.; Credi, A.; Lucarini, M. Reversible Mechanical Switching of Magnetic Interactions in a Molecular Shuttle. ChemistryOpen 2015, 4, 18-21. [CrossRef] [PubMed] 
65. Doistau, B.; Tron, A.; Denisov, S.A.; Jonusauskas, G.; McClenaghan, N.D.; Gontard, G.; Marvaud, V.; Hasenknopf, B.; Vives, G. Terpy(Pt-salphen)2 Switchable Luminescent Molecular Tweezers. Chem. Eur. J. 2014, 20, 15799-15807. [CrossRef] [PubMed]

66. Doistau, B.; Rossi-Gendron, C.; Tron, A.; McClenaghan, N.D.; Chamoreau, L.-M.; Hasenknopf, B.; Vives, G. Switchable platinum-based tweezers with $\mathrm{Pt}-\mathrm{Pt}$ bonding and selective luminescence quenching. Dalton Trans. 2015, 44, 8543-8551. [CrossRef] [PubMed]

67. Doistau, B.; Cantin, J.-L.; Chamoreau, L.-M.; Marvaud, V.; Hasenknopf, B.; Vives, G. Mechanical switching of magnetic interaction by tweezers-type complex. Chem. Commun. 2015, 51, 12916-12919. [CrossRef] [PubMed]

68. Doistau, B.; Benda, L.; Cantin, J.-L.; Chamoreau, L.-M.; Ruiz, E.; Marvaud, V.; Hasenknopf, B.; Vives, G. Six States Switching of Redox-Active Molecular Tweezers by Three Orthogonal Stimuli. J. Am. Chem. Soc. 2017, 139, 9213-9220. [CrossRef] [PubMed]

69. Shepherd, H.J.; Gural'skiy, I.Y.A.; Quintero, C.M.; Tricard, S.; Salmon, L.; Molnár, G.; Bousseksou, A. Molecular actuators driven by cooperative spin-state switching. Nat. Commun. 2013, 4, 2607. [CrossRef] [PubMed]

70. Cornia, A.; Seneor, P. The molecular way. Nat. Mater. 2017, 16, 505-506. [CrossRef] [PubMed]

71. Ferrando-Soria, J.; Vallejo, J.; Castellano, M.; Martínez-Lillo, J.; Pardo, E.; Cano, J.; Castro, I.; Lloret, F.; Ruiz-García, R.; Julve, M. Molecular magnetism, quo vadis? A historical perspective from a coordination chemist viewpoint. Coord. Chem. Rev. 2017, 339, 17-103. [CrossRef]

72. Estrader, M.; Salinas Uber, J.; Barrios, L.A.; Garcia, J.; Lloyd-Williams, P.; Roubeau, O.; Teat, S.J.; Aromí, G. A Magneto-optical Molecular Device: Interplay of Spin Crossover, Luminescence, Photomagnetism, and Photochromism. Angew. Chem. Int. Ed. 2017, 56, 15622-15627. [CrossRef] [PubMed]

(C) 2018 by the authors. Licensee MDPI, Basel, Switzerland. This article is an open access article distributed under the terms and conditions of the Creative Commons Attribution (CC BY) license (http://creativecommons.org/licenses/by/4.0/). 